\title{
Efficacy of axial TheraTogs on gait pattern in children with dyskinetic cerebral palsy: a randomized controlled trial
}

\author{
Shamekh Mohamed El-Shamy* (1) and Ehab Mohamed Abd El Kafy
}

\begin{abstract}
Background: TheraTogs promotes proprioceptive sense of a child with cerebral palsy and improves abnormal muscle tone, posture alignment, balance, and gait. Therefore, the aim of this study was to investigate the efficacy of TheraTogs orthotic undergarment on gait pattern in children with dyskinetic cerebral palsy. Thirty children with dyskinetic cerebral palsy were selected for this randomized controlled study. They were randomly assigned to (1) an experimental group that received TheraTogs orthotic undergarment ( $12 \mathrm{~h} /$ day, 3 days/week) plus traditional physical therapy for 3 successive months and (2) a control group that received only traditional physical therapy program for the same time period. Gait parameters were measured at baseline and after 3 months of intervention using Pro-Reflex motion analysis.
\end{abstract}

Results: Children in both groups showed significant improvements in the gait parameters $(P<0.05)$, with significantly greater improvements in the experimental group than in the control group.

Conclusions: The use of TheraTogs may have a positive effect to improve gait pattern in children with dyskinetic cerebral palsy.

Trial registration: This trial was registered in the ClinicalTrial.gov PRS (NCT03037697).

Keywords: Cerebral palsy, Dyskinesia, TheraTogs, Orthotic undergarment, Gait pattern

\section{Background}

Cerebral palsy $(\mathrm{CP})$ is a group of disorders of the development of movement and posture that occur as a result of a non-progressive lesion to the developing brain [1]. Children with $\mathrm{CP}$ usually have a variety of motor impairments, such as spasticity, involuntary movements, unsteady gait, and problems with balance that limit activities of daily living and self-care [2].

Dyskinetic cerebral palsy (DCP) is one of the most debilitating types of $\mathrm{CP}$ because it causes severe motor impairment [3]. Children with DCP experience abnormal muscle activity stemming from the simultaneous, sustained contraction of the agonist and antagonist muscles

\footnotetext{
*Correspondence: smshamy@uqu.edu.sa

Department of Physical Therapy, Faculty of Applied Medical Sciences, Umm Al-Qura University, Makkah, Saudi Arabia
}

(C) The Author(s). 2021 Open Access This article is licensed under a Creative Commons Attribution 4.0 International License, which permits use, sharing, adaptation, distribution and reproduction in any medium or format, as long as you give appropriate credit to the original author(s) and the source, provide a link to the Creative Commons licence, and indicate if changes were made. The images or other third party material in this article are included in the article's Creative Commons licence, unless indicated otherwise in a credit line to the material. If material is not included in the article's Creative Commons licence and your intended use is not permitted by statutory regulation or exceeds the permitted use, you will need to obtain permission directly from the copyright holder. To view a copy of this licence, visit http://creativecommons.org/licenses/by/4.0/.

during movement $[4,5]$, resulting in difficulties maintaining spatiotemporal trajectories and considerable variability in their movements [6]. The most common manifestations are athetosis, chorea, and dystonia [7]. These involuntary movements can cause discomfort, interfere with voluntary movements, and limit or even impede upper and lower limb functions [8,9].

Children with $\mathrm{CP}$ are often classified by severity of mobility limitation through the Gross Motor Function Classification System (GMFCS) [10]. This is a useful tool to identify levels of motor ability, guide treatment decisions, and allow estimation of the development of motor performance [11]. A common therapeutic goal for rehabilitation is to improve mobility and walking ability. Improved walking ability has a positive impact on achievement of daily activities and motivating social engagement [12]. 
Current intervention options, including physical and occupational therapies, pharmacological approaches, and deep brain stimulation, are often not successful or only partially successful in controlling symptoms. As a result, there is a need to investigate new non-invasive options for treating dyskinesia in children [13-15]. Physical therapy intervention is the major treatment for postural deviations in children with DCP. The designed exercise protocol is used to encourage adjustment and repositioning of skeletal segments which in turn produce static posture realignment. It has been reported that the exercise program is insufficient alone without additional physical therapy modalities to produce adaptive changes in postural control $[16,17]$.

TheraTogs orthotic undergarments have been developed to provide a gentle, passive force to correct alignment through the combination of a trunk-and-shorts system with a customized external strapping system. It is suggested that this system can improve joint stability, posture, and gait skills $[18,19]$. The purpose of this study was to investigate efficacy of TheraTogs orthotics undergarments on gait pattern in children with DCP.

\section{Methods}

\section{Design}

This single-blind randomized controlled study was approved by the Ethical Committee of the Faculty of Applied Medical Sciences, Umm Al Qura University (19MED-1-01-0004). Parents signed a consent form approving children participation. The children who participated in this study were enrolled from the physical therapy department, Maternity and Children Hospital, Makkah, Saudi Arabia. This trial was registered in the ClinicalTrial.gov PRS No NCT03037697.

\section{Participants}

Thirty children diagnosed with dyskinetic $\mathrm{CP}$ were recruited for this study. Their scores on the Gross Motor Function Classification System (GMFCS) were Levels I or II. The inclusion criteria for this study were age between 8 and 12 years; spasticity degree ranging between grades $1,1+$, and 2 according to the Modified Ashworth Scale (MAS); and the ability to understand and follow simple verbal instructions. The exclusion criteria were any fixed deformities that interfere with lower limb functions, cardiac or respiratory conditions that are affected by exercise, and the presence of seizures or lower limb orthopedic surgery in the preceding 12 months or botulinum toxin injections in the previous 6 months. During the study, children will not receive any treatment to improve the gait pattern other than the study intervention. They did not participate in any previous trials with orthotic undergarment, adhesive tape, or spiral strapping to the lower limbs and axial trunk.

\section{Randomization}

In order to eliminate bias in the treatment assignment, the children will be randomized into both groups. Randomization was performed utilizing the SPSS computer program (version 16; SPSS Inc., Chicago, IL). Assignment happened before the underlying appraisal. The control group received the traditional physical therapy program. The experimental group received TheraTogs orthotic undergarments in addition to the same traditional program given to the control group. The experimental design is shown as a flow diagram in Fig. 1.

\section{Gait parameters evaluation}

All children were assessed for gait parameters before the treatment and at the end of 3 months of treatment by the same examiner using the Pro-Reflex motion analysis system (Qualisys; Qualisys Inc., Goeteborg, Sweden). This system consists of an 8-m-long wooden walkway, a three-dimensional infrared camera system with six cameras spaced equally on both sides of the walkway, and a personal computer with Q-Trace software installed to analyze the motion pattern. This system incorporates 9$\mathrm{mm}$-diameter reflective markers for optimizing the focus settings of the camera. Twelve markers were fixed bilaterally on the following landmarks: the superior border of the patella, laterally at the knee joint line, tibial tuberosity, lateral malleolus, heel posterior of the calcaneus, and between the second and third metatarsal heads. The procedures of calibration, capture, and analysis of data were performed according to guidelines in the manual of the motion system. The selected gait parameters were evaluated: velocity $(\mathrm{m} / \mathrm{s})$, stride length $(\mathrm{m})$, cadence (steps/min), and percent of time spent in double limb support (\%) [20, 21].

\section{Interventions}

\section{Traditional physical therapy program}

Children in both groups got the traditional physical therapy program, which included reflex-inhibiting exercises for both lower limbs, stretching exercises, strengthening exercises for muscles of the trunk and both lower limbs, proprioceptive training, balance exercises in all directions from a standing position using a wooden balance board, and gait training ( $1 \mathrm{~h} /$ day, 3 days/week for 3 consecutive months) [22].

\section{TheraTogs orthotic application}

Children in the experimental group received the strapping technique using TheraTogs orthotic undergarment strapping system (TheraTogs ${ }^{\mathrm{ma}}$ Inc., Telluride, USA). TheraTogs are made of a patented, proprietary, machine washable, compose fabric consisting of nylon and spandex with an inner foam that gently grips the skin and the underlying soft tissues and a velcro-sensitive outer 


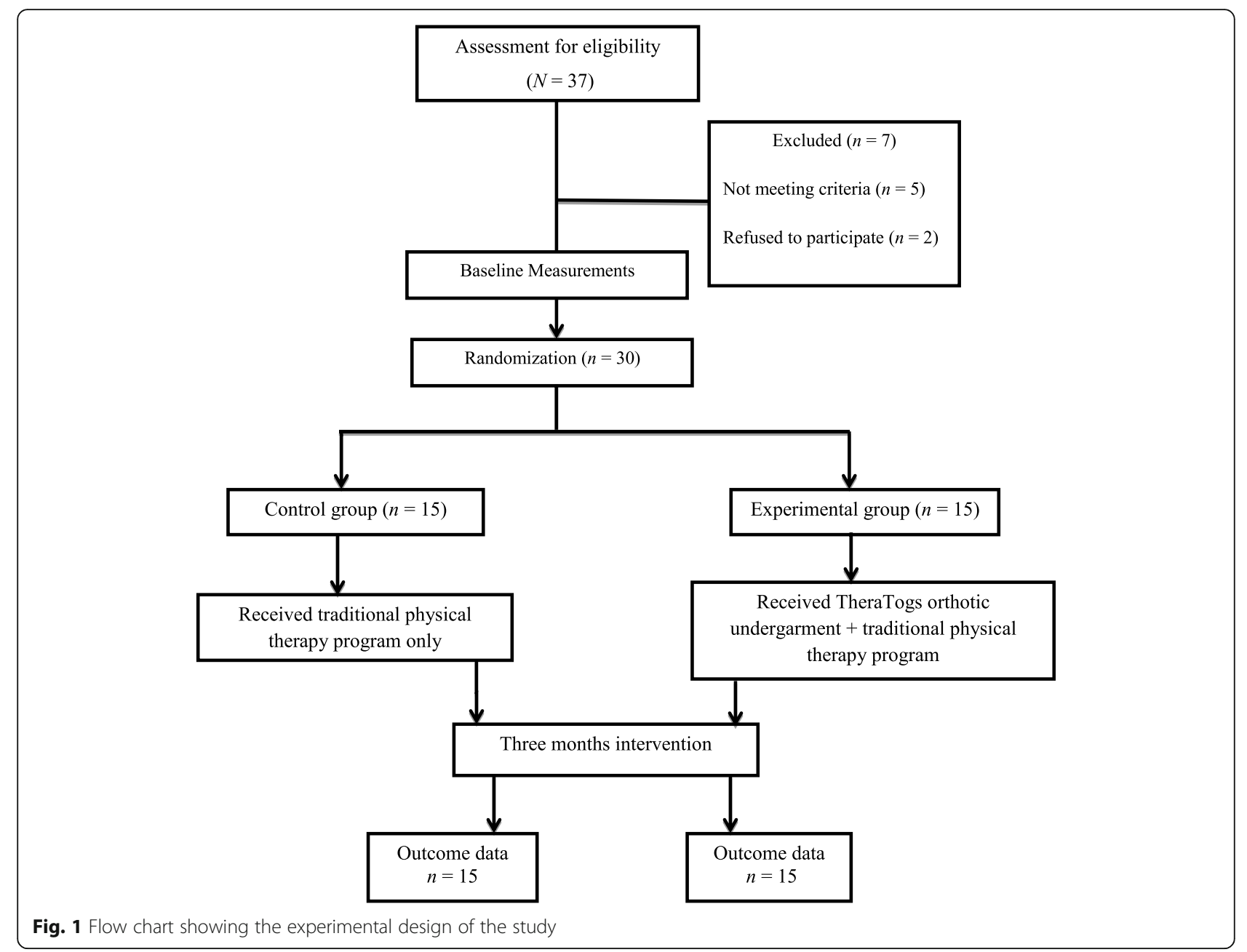

layer to which therapist can affix elastic strapping, to effectively influence your patient's movement, stability, posture, and gait. A TheraTogs orthotic undergarment consists of sleeveless tank-Top, two shorts (Hipster) each with two thigh cuffs and limb cuffs. All parts fabricated from nylon and spandex with a foam layer made of aqueous-based elastomeric urethane and a variety of elasticized straps. They are designed to be worn directly on the skin as undergarments that allow unimpeded toileting.

TheraTogs system gives the wearer a comfortable, breathable Latex-free "second skin" on his torso and thighs, providing vertical stiffness to reinforce postural stability and horizontal stretch for child compression and a comfortable fit. The following precautions will be considered when applying this strapping technique; the child should be comfortable without feeling constriction, itching, or circulatory impairment. The garments should be snug against the skin, with no significant gaps, folds, or loose material. Well-fit garments are snug enough that they effectively grip the wearer's skin, without slipping. Each child will have his own TheraTogs orthotic undergarment, and it will not be allowed for any child to share his orthosis with others for several reasons: to avoid any infectious disease transformation, each child has its special size which may not fit with other, and the way of fitting and strapping technique will differ from one child to other according to his case.

The wearing schedule for this study was adopted and modified from Flanagan et al. [18]. Children wore TheraTogs orthotic undergarment and strapping system under their usual clothes so it was not annoying or disturbing. One week before starting the training program, the participating children wore their TheraTogs as preparatory stage without application of any exercise program with gradually increasing the worn time till reaching the $12 \mathrm{~h}$ per day, to allow the children to become acclimated to the system.

\section{Statistical analysis}

Comparison of assessments before and immediately after the treatment in each group (experimental or control) was performed using a paired $t$ test. The comparison of assessments between both groups before and 
immediately after treatment was carried out using an unpaired $t$ test. The Statistical Package for the Social Sciences (SPSS) version 16.00 was used for data analysis. $P$ values less than 0.05 were considered to be statistically significant.

\section{Results}

Thirty children with DCP (18 boys and 12 girls) were included in this study. The children were randomly assigned to one of two equal-sized groups ( $n=15$ each). The demographic and clinical characteristics of the children were similar in both groups (Table 1).

Baseline measurements revealed no significant differences in the mean values of gait parameters (velocity, stride length, cadence, and percent of time spent in double limb support) between the experimental and control groups $(P>0.05)$ (Table 2). However, there was a significant difference between the mean values of gait parameters obtained at the baseline and post-treatment assessments $(P<0.05)$. The children in the experimental group exhibited improvements in their gait parameters compared with children in the control group (Table 2).

\section{Discussion}

The purpose of this study was to investigate the efficacy of the TheraTogs on gait pattern in children with DCP; comparison of the difference between the gait parameters was analyzed and compared between conditions with and without the TheraTogs. The results showed that the selected gait parameters of the children with DCP wearing the TheraTogs were significantly improved compared to those who did not wear the TheraTogs.

Cerebral palsy causes nervous system injury and results in lower limb spasticity, contracture, lack of coordination, muscle weakness, and inability to move independently in children [23, 24]. When comparing the number of motor units recruited during a voluntary contraction, the children with $\mathrm{CP}$ had less units than the healthy children [25]. Along with muscular spasm and joint contracture, the problems cause abnormal gait, joint restriction, and loss of functional activity [26]. Ambulation is an important functional activity, as a previous study of Kadhim and Miller [26] pointed out that $90 \%$ of children with CP had instability problems during gait, and $54 \%$ of the children were unable to walk alone. Therefore, the children with $\mathrm{CP}$ needed more training and assistance for walking in the rehabilitation treatment.

TheraTogs is certainly a viable and useful physical therapy intervention tool for modulating biomechanical malalignment and poor postural control in children having CP. Many scientists proposed that therapeutic strapping would provide the foundation for increasing proprioceptive and tactile awareness, restoring optimal muscle length to provide a basis for normal firing and recruitment patterns and orienting the muscle force along normal vectors in the frontal and sagittal planes [27-30].

TheraTogs and strapping system are designed to improve body awareness, postural stability, and functional joint alignment during therapy as well as during performance of activities of daily living. Many authors supported that lower extremity strapping by application of TheraTogs and strapping system could (1) gently rotate the thigh as needed to improve knee joint alignment and function and also to improve the recruitment of muscles that cross the hip joint in swing phase, (2) gently rotate the leg as needed to improve foot alignment and function, (3) reduce hip adduction and keep the legs apart to correct scissoring gait, and (4) reduce trunk, hip, and knee flexion [19, 31-33].

Table 1 Demographical and clinical characteristics of the children at baseline

\begin{tabular}{|c|c|c|c|c|}
\hline Characteristics & $\begin{array}{l}\text { Experimental group } \\
(n=15)\end{array}$ & $\begin{array}{l}\text { Control group } \\
(n=15)\end{array}$ & $T$ value & $P$ value \\
\hline Age (years) & $10.53 \pm 1.24$ & $10.13 \pm 1.25$ & 0.88 & 0.364 \\
\hline Weight (Kg) & $33.13 \pm 1.73$ & $32.4 \pm 1.92$ & 1.09 & 0.281 \\
\hline Height (meter) & $1.35 \pm 1.34$ & $1.34 \pm 1.24$ & 0.12 & 0.333 \\
\hline Sex (boy/girl) & $10 / 5$ & $8 / 7$ & -0.73 & 0.473 \\
\hline \multicolumn{5}{|l|}{ Spasticity grades } \\
\hline 1 & 3 & 4 & -0.63 & 0.464 \\
\hline $1+$ & 6 & 6 & & \\
\hline 2 & 6 & 5 & & \\
\hline \multicolumn{5}{|l|}{ GMFCS level } \\
\hline I & 7 & 6 & 0.47 & \\
\hline II & 8 & 9 & & 0.724 \\
\hline
\end{tabular}

GMFCS Gross Motor Function Classification System

Level of significance at $P<0.05$ 
Table 2 Pre and post-treatment mean values of gait parameters within each group and between groups

\begin{tabular}{|c|c|c|c|c|c|c|c|}
\hline \multirow[t]{2}{*}{ Parameters } & & \multirow{2}{*}{$\begin{array}{l}\text { Experimental } \\
\text { group }\end{array}$} & \multirow{2}{*}{$\begin{array}{l}\text { Control } \\
\text { group }\end{array}$} & \multicolumn{2}{|c|}{$\mathbf{9 5 \%}$ confidence interval of the difference } & \multirow[t]{2}{*}{$T$ value } & \multirow[t]{2}{*}{$P$ value } \\
\hline & & & & Lower & Upper & & \\
\hline \multirow[t]{4}{*}{ Velocity (m/s) } & Pre & $0.63 \pm 0.29$ & $0.64 \pm 0.26$ & -0.03 & 0.01 & -1.03 & 0.311 \\
\hline & Post & $0.80 \pm 0.01$ & $0.73 \pm 0.02$ & 0.05 & 0.08 & 9.92 & $<0.001$ \\
\hline & $T$ value & -28.08 & -20.82 & & & & \\
\hline & $P$ value & $<0.001$ & $<0.001$ & & & & \\
\hline \multirow[t]{4}{*}{ Stride length (m) } & Pre & $0.71 \pm 0.37$ & $0.70 \pm 0.30$ & -0.02 & 0.03 & 0.37 & 0.714 \\
\hline & Post & $0.92 \pm 0.20$ & $0.81 \pm 0.32$ & 0.09 & 0.13 & 11.35 & $<0.001$ \\
\hline & $T$ value & -29.56 & -21.72 & & & & \\
\hline & $P$ value & $<0.001$ & $<0.001$ & & & & \\
\hline \multirow[t]{4}{*}{ Cadence (steps/min) } & Pre & $87.6 \pm 3.25$ & $88.4 \pm 2.16$ & -2.86 & 1.26 & -0.79 & 0.434 \\
\hline & Post & $107.2 \pm 4.72$ & $94.9 \pm 2.55$ & 9.43 & 15.1 & 8.85 & $<0.001$ \\
\hline & $T$ value & -20.5 & 12.68 & & & & \\
\hline & $P$ value & $<0.001$ & $<0.001$ & & & & \\
\hline \multirow{4}{*}{$\begin{array}{l}\text { Percent of time spent in double } \\
\text { limb support (\%) }\end{array}$} & Pre & $35 \pm 2$ & $34.5 \pm 1.88$ & -0.98 & 1.92 & 0.65 & 0.516 \\
\hline & Post & $27.47 \pm 1.46$ & $30.2 \pm 1.32$ & -3.77 & -1.69 & -5.38 & $<0.001$ \\
\hline & $T$ value & 12.38 & 15.08 & & & & \\
\hline & $P$ value & $<0.001$ & $<0.001$ & & & & \\
\hline
\end{tabular}

Level of significance at $P<0.05$

The findings of this study agree with that of El Fiky et al. [29]; they revealed that using of TheraTogs for a long period might act as a continuous reflex-inhibiting pattern for the abnormal internal rotation and adducted hip pattern of the involved spastic limb. This inhibitory mechanism might help in dampening the continuing reciprocal inhibiting pattern of these overexcited groups on the antagonist groups facilitating their action [29].

The study by Chang et al. [34] aimed to evaluate the effects of external strap orthosis on plantar pressure and gait parameters in children with CP. They found that the plantar pressure and spatiotemporal gait analysis indicated the potential use of external strap orthosis to improve the gait speed, stride length, and cadence and influence the foot motion and path of pressure trajectory in the children with CP. The elastic force of the orthosis can provide immediate assistance to correct the leg alignment and improve the gait performance. The current results support the importance of applying a customized external strap orthosis for the child in the treadmill ambulation training [34].

The results of the present study are consistent with those of Jung et al.'s [35]; they showed that the spatiotemporal gait variables of the children with $\mathrm{CP}$ wearing the TheraTogs were significantly improved compare to those who did not wear the TheraTogs. The results can suggest that the use of TheraTogs in children with $\mathrm{CP}$ may have positive effect to improve the gait ability [35].

Abd El-Kafy studied the clinical impact of ground reaction orthoses and TheraTogs in gait parameters of children with spastic diplegia CP. The results of the study showed that the use of TheraTogs and the ground reaction orthoses during treatment of children with $\mathrm{CP}$ over 12 weeks led to a greater improvement in their gait than using conventional treatment without TheraTogs [36].

However, this study has some limitations, namely, (1) the small sample size does not allow the generalization of the results, (2) the lack of participants with other diagnosed types of CP, (3) the long-term effect was not be investigated, (4) the effect of the physical therapy program in both groups also limits the ability to isolate the contribution of the TheraTogs orthotic undergarment alone. The results of the present study are encouraging, but further studies that include a larger number of children with $\mathrm{CP}$ would provide results that could be more easily generalized. Long-term effects of the orthosis on functional activity also needed to be investigated. Future studies investigating the effect of TheraTogs orthotic undergarment and its role in improving muscle strength and energy expenditure in children with $\mathrm{CP}$ may be useful for guiding clinical practice.

\section{Conclusion}

The results of the present study showed that the gait pattern of the children with DCP wearing the TheraTogs was significantly improved compared to those who did not wear the TheraTogs. The results can suggest that the use of TheraTogs may have positive effect to improve the gait pattern in children with DCP. 


\section{Abbreviations}

CP: Cerebral palsy; DCP: Dyskinetic cerebral palsy; GMFCS: Gross Motor Function Classification System; MAS: Modified Ashworth scale

\section{Acknowledgements}

The authors would like to thank the Deanship of Scientific Research at Umm Al-Qura University for supporting this work by Grant Code: 19-MED-1-010004.

\section{Authors' contributions}

SME and EMA conceived and designed the study and conducted the data collection. SME and EMA analyzed and interpreted the data in addition to reviewing the final results. SME and EMA provided logistical support and wrote the initial and final drafts of the article. SME and EMA are responsible for the findings and have critically reviewed and approved the final draft of the article. The authors read and approved the final manuscript.

\section{Funding}

The authors confirm that there is no financial support.

\section{Availability of data and materials}

The datasets generated during and/or analyzed during the current study are available from the corresponding author on reasonable request.

\section{Declarations}

\section{Ethics approval and consent to participate}

The study was approved by the Ethical Committee of the Faculty of Applied Medical Sciences, Umm Al Qura University (19-MED-1-01-0004). Parents of all participants signed a written informed consent before starting the study.

\section{Consent for publication}

\section{Competing interests}

The authors declare that they have no competing interests.

\section{Received: 25 February 2021 Accepted: 10 May 2021}

Published online: 23 June 2021

\section{References}

1. Christensen D, Van Naarden Braun K, Doernberg NS, Maenner MJ, Arneson $\mathrm{CL}$, Durkin MS, et al. Prevalence of cerebral palsy, cooccurring autism spectrum disorders, and motor functioning-autism and developmental disabilities monitoring network USA 2008. Dev Med Child Neurol. 2014; 56(1):59-65. https://doi.org/10.1111/dmcn.12268.

2. Stavsky M, Mor O, Mastrolia SA, Greenbaum S, Than NG, Erez O. Cerebral palsy-trends in epidemiology and recent development in prenatal mechanisms of disease, treatment, and prevention. Front Pediatr. 2017;5:21.

3. Monbaliu E, Himmelmann K, Lin JP, Ortibus E, Bonouvrié L, Feys H, et al. Clinical presentation and management of dyskinetic cerebral palsy. Lancet Neurol. 2017;16(9):741-9. https://doi.org/10.1016/S1474-4422(17)30252-1.

4. Graham HK, Rosenbaum P, Paneth N, Dan B, Lin JP, Damiano DL, et al. Cerebral palsy. Nat Rev Dis Primers. 2016;2:1-24.

5. Monbaliu E, De Cock P, Mailleux L, Dan B, Feys H. The relationship of dystonia and choreoathetosis with activity, participation and quality of life in children and youth with dyskinetic cerebral palsy. Eur J Paediatr Neurol. 2017;21(2):327-35. https://doi.org/10.1016/j.ejpn.2016.09.003.

6. Brégou Bourgeois A, Mariani B, Aminian K, Zambelli PY, Newman CJ. Spatiotemporal gait analysis in children with cerebral palsy using, foot-worn inertial sensors. Gait Posture. 2014;39(1):436-42. https://doi.org/10.1016/j.ga itpost.2013.08.029.

7. Monbaliu E, de Cock P, Ortibus E, Heyrman L, Klingels K, Feys H. Clinical patterns of dystonia and choreoathetosis in participants with dyskinetic cerebral palsy. Dev Med Child Neurol. 2016;58(2):138-44. https://doi.org/1 $0.1111 /$ dmcn.12846.

8. Preel M, Rackauskaite $G$, Larsen ML, Laursen $B$, Lorentzen J, Born AP, et al. Children with dyskinetic cerebral palsy are severely affected as compared to bilateral spastic cerebral palsy. Acta Paediatr. 2019;108(10):1850-6. https:// doi.org/10.1111/apa.14806
9. Stewart K, Harvey A, Johnston LM. A systematic review of scales to measure dystonia and choreoathetosis in children with dyskinetic cerebral palsy. Dev Med Child Neurol. 2017;59(8):786-95. https://doi.org/10.1111/dmcn.13452.

10. Paulson A, Vargus-Adams J. Overview of four functional classification systems commonly used in cerebral palsy. Children. 2017:4(4):30.

11. Goh YR, Choi JY, Kim SA, Park J, Park ES. Comparisons of severity classification systems for oropharyngeal dysfunction in children with cerebral palsy: relations with other functional profiles. Res Dev Disabil. 2018; 72:248-56. https://doi.org/10.1016/j.ridd.2017.12.002.

12. Reid SM, Carlin JB, Reddihough DS. Using the gross motor function classification system to describe patterns of motor severity in cerebral palsy. Dev Med Child Neurol. 2011;53(11):1007-12. https://doi.org/10.1111/j.14698749.2011.04044.x

13. Novak I. Evidence-based diagnosis, health care, and rehabilitation for children with cerebral palsy. J Child Neurol. 2014;29(8):1141-56. https://doi. org/10.1177/0883073814535503.

14. Bertucco M, Sanger TD. Current and emerging strategies for treatment of childhood dystonia. J Hand Ther. 2015;28(2):185-93. https://doi.org/10.1016/ j.jht.2014.11.002.

15. Fehlings D, Brown L, Harvey A, Himmelmann K, Lin JP, Macintosh A, et al. Pharmacological and neurosurgical interventions for managing dystonia in cerebral palsy: a systematic review. Dev Med Child Neurol. 2018;60(4):35666. https://doi.org/10.1111/dmcn.13652.

16. Novak I, Mcintyre S, Morgan C, Campbell L, Dark L, Morton N, et al. A systematic review of interventions for children with cerebral palsy: state of the evidence. Dev Med Child Neurol. 2013;55(10):885-910. https://doi.org/1 $0.1111 / d m c n .12246$.

17. Das SP, Ganesh GS. Evidence-based approach to physical therapy in cerebral palsy. Indian J Orthop. 2019;53(1):20-34. https://doi.org/10.4103/ ortho.IJOrtho_241_17.

18. Flanagan A, Krzak J, Peer M, Johnson P, Urban M. Evaluation of short-term intensive orthotic garment use in children who have cerebral palsy. Pediatr Phys Ther. 2009;21(2):201-4. https://doi.org/10.1097/PEP.0b013e3181a347ab.

19. Ehlert R, Manfio EF, Heidrich RO, Goldani R. Cerebral palsy: Influence of TheraTogs $^{\oplus}$ on gait, posture and in functional performance. Fisioter Mov. 2017:30(2):307-17. https://doi.org/10.1590/1980-5918.030.002.ao11.

20. Abd El-Kafy EM, El-Basatiny HM. Effect of postural balance training on gait parameters in children with cerebral palsy. Am J Phys Med Rehabil. 2014; 93(11):938-47. https://doi.org/10.1097/PHM.0000000000000109.

21. El-Shamy SM, Eid MA, El-Banna MF. Effect of extracorporeal shock wave therapy on gait pattern in hemiplegic cerebral palsy: a randomized controlled trial. Am J Phys Med Rehabil. 2014;93(12):1065-72. https://doi. org/10.1097/PHM.0000000000000133.

22. Levitt $\mathrm{S}$, Addison A. Treatment of cerebral palsy and motor delay. 6th ed. Hoboken: Wiley; 2019. p. 157-308.

23. Ko $\mathrm{H}, \mathrm{Kim} J \mathrm{H}$, Lee $\mathrm{BH}$. Relationships between lower limb muscle architecture and activities and participation of children with cerebral palsy. $J$ Exerc Rehabil. 2013;9(3):368-74. https://doi.org/10.12965/jer.130045.

24. Lucareli PR, Lima Mde O, Lucarelli JG, Lima FP. Changes in joint kinematics in children with cerebral palsy while walking with and without a floor reaction ankle-foot orthosis. Clinics. 2007;62(1):63-8.

25. Pool D, Blackmore AM, Bear N, Valentine J. Effects of short-term daily community walk aide use on children with unilateral spastic cerebral palsy. Pediatr Phys Ther. 2014;26(3):308-17. https://doi.org/10.1097/PEP. 0000000000000057.

26. Kadhim M, Miller F. Crouch gait changes after planovalgus foot deformity correction in ambulatory children with cerebral palsy. Gait Posture. 2014; 39(2):793-8. https://doi.org/10.1016/j.gaitpost.2013.10.020.

27. Elliott CM, Reid SL, Alderson JA, Elliott BC. Lycra arm splints in conjunction with goal-directed training can improve movement in children with cerebral palsy. NeuroRehabilitation. 2011;28(1):47-54. https://doi.org/1 0.3233/NRE-2011-0631.

28. Harel $Y$, Atun-Einy O, Lotan M. Pressure undergarments as means to improve sensory motor, function and emotional behavior of a child with autism spectrum disorder: a history case report. Autism-Open Access. 2017; 7:220.

29. El Fiky A, Elsodany A, Abd El-Kafy E. Effect of TheraTogs orthotic undergarment on postural balance control, risk of fall, and walking abilities in Saudi individuals with chronic stroke. Jokull J. 2016;66(5):23-35.

30. Richards A, Morcos S, Rethlefsen S, Ryan D. The use of TheraTogs versus twister cables in the treatment of in-toeing during gait in a child with spina 
bifida. Pediatr Phys Ther. 2012;24(4):321-6. https://doi.org/10.1097/PEP.0b013 e318268a9c7.

31. Almeida KM, Fonseca ST, Figueiredo PRP, Aquino AA, Mancini MC. Effects of interventions with therapeutic suits (clothing) on impairments and

functional limitations of children with cerebral palsy: a systematic review. $\mathrm{Br}$ J Phys Ther. 2017;21(5):307-20. https://doi.org/10.1016/j.bjpt.2017.06.009.

32. Romeo DM, Specchia A, Sini F, Bompard S, Di Polito A, Del Vecchio A, et al. Effects of Lycra suits in children with cerebral palsy. Eur J Paediatr Neurol. 2018;22(5):831-6. https://doi.org/10.1016/j.ejpn.2018.04.014.

33. Coghill JE, Simkiss DE. Question 1. Do Lycra garments improve function and movement in children with cerebral palsy? Arch Dis Child. 2010;95(5):393-5. https://doi.org/10.1136/adc.2009.178624.

34. Chang WD, Chang NJ, Lin HY, Lai PT. Changes of plantar pressure and gait parameters in children with mild cerebral palsy who used a customized external strap orthosis: a crossover study. Biomed Res Int. 2015;2015:813942.

35. Jung J, Jeong J, Lee D, Hong S, Lee K, Lee G. Comparison of spatiotemporal gait parameters depending on using TheraTogs in children with spastic cerebral palsy. Curr Pediatr Res. 2019;23(1):1-5.

36. Abd El-Kafy EM. The clinical impact of orthotic correction of lower limb rotational deformities in children with cerebral palsy: a randomized controlled trial. Clin Rehabil. 2014;28(10):1004-14. https://doi.org/10.1177/02 69215514533710.

\section{Publisher's Note}

Springer Nature remains neutral with regard to jurisdictional claims in published maps and institutional affiliations.

\section{Submit your manuscript to a SpringerOpen ${ }^{\circ}$ journal and benefit from:}

- Convenient online submission

- Rigorous peer review

- Open access: articles freely available online

- High visibility within the field

- Retaining the copyright to your article

Submit your next manuscript at $\boldsymbol{\nabla}$ springeropen.com 